\title{
Rancang Bangun Sistem Persediaan Alat Tulis Kantor Berbasis Web Pada Perumdam Tirta Kerta Raharja Kabupaten Tangerang
}

\author{
Nur Azizah $^{* 1}$, Nurlaila Suci Rahayu ${ }^{2}$, Dewi Anjani ${ }^{3}$ \\ Program Studi Sistem Informasi Universitas Raharja, Program Studi Manajemen Informatika \\ Universitas Raharja \\ Email: ${ }^{* 1}$ nur.Azizah@ raharja.info, ${ }^{2}$ nurlaila@ raharja.info, ${ }^{3}$ dewi.anjani@ raharja.info
}

\begin{abstract}
Abstrak
Sistem persediaan alat tulis kantor yang akurat dan up to date sangatlah dibutuhkan oleh pihak perusahaan. Dalam proses persediaan alat tulis kantor Perumdam Tirta Kerta Raharja Kabupaten Tangerang yang dilakukan pada saat ini masih manual sehingga kurang efektif, dikarenakan sub bagian gudang memanfaatkan dokumen persediaan alat tulis kantor berupa form pengajuan dan menginput data persediaan alat tulis kantor secara manual sehingga proses monitoring sulit dan rentan hilang atau rusaknya dokumen. Oleh karena itu, perlu adanya perancangan sistem informasi persediaan alat tulis kantor berbasis web yang sudah terkomputerisasi agar dapat memudahkan para penggunanya. Dengan adanya sistem persediaan alat tulis kantor berbasis web yang terkomputerisasi dapat memudahkan sub bagian gudang dalam melakukan penginputan data sehingga monitoring stok persediaan dilakukan secara berkala agar lebih akurat dan optimal. Metode pengumpulan data yang dilakukan dengan cara observasi, wawancara, serta studi pustaka dari berbagai penelitian, sedangkan metode analisa sistem yang dilakukan menggunakan metode PIECES dan metode perancangan menggunakan UML (Unified Modelling Language) serta PHP bahasa pemrograman dan MysQL sebagai database. Hal ini menjadi dasar pemikiran bagaimana peneliti menganalisa sistem persediaan alat tulis kantor yang ada pada Perumdam Tirta Kerta Raharja Kabupaten Tangeran sehingga dapat memudahkan dalam kinerja tersebut agar lebih efektif, efisien serta akurat.
\end{abstract}

Kata Kunci : Sistem Informasi, ATK, dan Web.

\begin{abstract}
An office stationery inventory system that is accurate and up to date is needed by the company. In the process of stationery inventory of the Tirta Kerta Raharja District Office in Tangerang Regency, which is done at this time is still manual so it is less effective, because the warehouse sub-section utilizes office stationery inventory documents in the form of submission forms and inputs office stationery inventory data manually so that the monitoring process is difficult and vulnerable to loss or damage to documents. Therefore, it is necessary to design a computerized web-based office stationery inventory information system in order to facilitate its users. With the computerized web-based office stationery inventory system can facilitate the warehouse subsection in inputting data so that inventory monitoring is carried out regularly to make it more accurate and optimal. Data collection methods are done by observation, interviews, and literature studies from various studies, while the system analysis method is done using the PIECES method and the design method uses UML (Unified Modeling Language) and PHP programming language and MysQL as a database. This is the rationale for how researchers analyze the existing office stationery inventory system at the Tirta Kerta Raharja Public Corporation in the District of Tangeran so that it can facilitate the performance to be more effective, efficient and accurate.
\end{abstract}


Keyword: Information System, ATK, and the web.

\section{Pendahuluan}

Perkembangan teknologi informasi dari waktu ke waktu terus mengalami peningkatan. Setiap tahunnya selalu berevolusi mengubah perspektif kita terhadap dunia, memberikan pengaruh yang sangat besar dalam kehidupan sehari-hari. Oleh karena itu, perkembangan teknologi informasi telah menjadi sumber daya utama bagi sebuah perusahaan. Dengan adanya teknologi informasi dapat memudahkan banyak orang untuk belajar serta mendapatkan informasi yang dibutuhkan secara akurat, efektif dan efisiensi sehingga para pengguna dapat memperolehnya dengan mudah. Perumdam Tirta Kerta Raharja Kabupaten Tangerang adalah salah satu Badan Usaha Milik Daerah yang bergerak dalam bidang air bersih maupun air minum yang dimiliki oleh Pemerintah Kabupaten Tangerang. Pada persediaan alat tulis kantor masih manual yaitu masih menggunakan hardcopy atau fisik kertas, sehingga proses monitoring terhambat dan rentan hilang. Dengan melihat permasalahan diatas, peneliti tertarik untuk membuat sebuah sistem yang berbasis web yang sudah memiliki database agar lebih memudahkan dari tahap permohonan monitoring alat tulis kantor secara berkala pada Perumdam Tirta Kerta Raharja Kabupaten Tangerang sehingga sub bagian gudang pun dapat langsung mengubah ketika terjadi pemasukan dan pengeluaran.

\section{TINJAUAN PUSTAKA}

\section{Sistem Informasi}

Sistem Informasi adalah suatu sistem di dalam suatu organisasi yang mempertemukan kebutuhan pengolahan data transaksi harian, mendukung operasi, bersifat manajerial dan kegiatan strategi dari suatu organisasi serta menyediakan pihak luar tertentu dengan laporan-laporan yang diperlukan. [1]

\section{Informasi}

Informasi adalah data yang telah diolah menjadi sebuah bentuk yang lebih berarti bagi penerimanya, dan bermanfaat dalam mengambil sebuah keputusan. [2]

\section{Persediaan}

Persediaan adalah suatu model yang umum digunakan untuk menyelesaikan masalah yang terkait dengan usaha pengendalian bahan baku maupun barang jadi dalam suatu aktivitas perusahaan. [3] Pendapat lain menyatakan bahwa persediaan merupakan persediaan bahan baku mempunyai kedudukan yang penting dalam perusahaan karena persediaan bahan baku sangat besar pengaruhnya terhadap kelancaran proses produksi. [4]

\section{Alat Tulis Kantor (ATK)}

Alat Tulis Kantor (ATK) adalah benda-benda yang dipakai habis dalam pelaksanaan dalam pekerjaan sehari-hari dari pegawai-pegawai tata usaha. [5]

\section{Web}

Website adalah kumpulan halaman-halaman yang digunakan untuk menampilkan informasi, teks, gambar diam atau bergerak, animasi, suara, dan atau gabungan dari semuanya baik yang bersifat dinamis yang membentuk satu rangkaian bangunan yang saling terkait, masing-masing dihubungkan dengan jaringan-jaringan halaman. [6] 


\section{Metode Penelitian}

Metode yang peneliti gunakan pada penelitian ini adalah:

1. Metode Pengumpulan Data

Adapun metode pengumpulan data yang ada dalam Penelitian Perancangan Sistem Informasi Persediaan Alat Tulis Kantor Berbasis Web Pada Perumdam Tirta Kerta Raharja Kabupaten Tangerang sebagai berikut:

\section{a. Metode Pengamatan (Observasi)}

Pada metode ini peneliti melakukan analisa secara langsung terhadap masalah yang terkait mengenai persediaan alat tulis kantor Perumdam Tirta Kerta Raharja Kabupaten Tangerang saat ini, sehingga peneliti dapat mengumpulkan data yang menunjang permasalahan yang ada.

b. Metode wawancara (Interview)

Peneliti melakukan dengan tanya jawab secara langsung kepada narasumber untuk mendapatkan informasi yang berhubungan dengan Persediaan alat tulis kantor pada Perumdam Tirta Kerta Raharja Kabupaten Tangerang, agar peneliti dapat memahami hal yang akan diteliti dan tepat serta akurat.

\section{c. Metode Studi Pustaka (Library Research)}

Metode studi pustaka dilakukan untuk menunjang metode observasi dan wawancara sehingga membantu peneliti dalam menulis laporan karena dengan metode pustaka peneliti dapat mempelajari literature yang berkaitan dengan permasalahan yang dibahas. Pengumpulan informasi dilakukan dengan cara membaca dan mempelajari buku- buku yang terkait dengan laporan penelitian pada perpustakaan, dan juga mengumpulkan informasi yang didapat melalui internet.

2. Metode Analisa

Metode analisa yang peneliti gunakan yaitu menggunakan metode analisis PIECES (Performance, Information, Economics, Control, Efficiency, Service) sebagai metode analisa sistem yang bertujuan untuk memecahkan sebuah masalah. Peneliti menggunakan metode ini dikarenakan untuk memperbaiki performa pendataan persediaan menjadi lebih baik, dan untuk mengurangi kesalahan dalam mengelola data persediaan.

\section{LITERATURE REVIEW}

Berikut beberapa daftar literature review yang digunakan didalam penelitian ini:

1. Penelitian yang dilakukan oleh Rahayu Sri dkk, (Januari 2015) dalam CCIT Journal yang berjudul "Sistem Persediaan Alat Tulis Kantor Sebagai Penunjang Pengambilan Keputusan Bagian Logistik Di Perguruan Tinggi Raharja" tahapan dalam penelitian ini adalah wawancara dan observasi. Hasil analisa menggunakan Bahasa pemodelan UML (unified Modelling Language). [7]

2. Penelitian yang dilakukan oleh Saryani dkk, (Agustus 2019) dalam Technomedia Journal yang berjudul "Sistem Informasi Inventory Pemasukan Dan Pengeluaran Data Barang ATK Pada Kelurahan Karangsari" Metode dalam penelitian ini yaitu melakukan observasi pada Kelurahan Karangsari, serta penggambaran dalam bentuk UML (Unified Modelling Language). [8]

3. Penelitian yang dilakukan oleh Winarso, dan Aryanto dalam Jurnal FASILKOM (September 2016), yang berjudul "Sistem Informasi Persediaan Alat Tulis Kantor Studi Kasus Pada Pt Bank Muamalat Indonesia Cabang Pekanbaru” [9] 
4. Penelitian yang dilakukan oleh Tika Yuli Lestari dan Didik Setiyadi Pada tahun (Juni 2019), yang berjudul "Sistem Informasi Persediaan Alat Tulis Kantor Pada PT

Berjaya Sally Ceria Jakarta". Sistem ini dibuat menggunakan bahasa pemograman visual basic.net serta menggunakan database sql server dan juga proses reporting menggunakan Crystal Report Viewer serta metode pengembangan sistem yang digunakan adalah metode RAD (Rapid Application development). [10]

\section{Hasil Dan Pembahasan}

Prosedur sistem pengadaan barang alat tulis kantor pada Perumdam Tirta Kerta Raharja Kabupaten Tangerang saat ini. Untuk menganalisa sistem yang sedang berjalan, peneliti menggunakan program Unified Modelling Language (UML), yang terdiri dari mulai membuat Use Case Diagram, Activity Diagram dan Sequence Diagram. Seperti ditunjukan pada gambar dibawah ini:

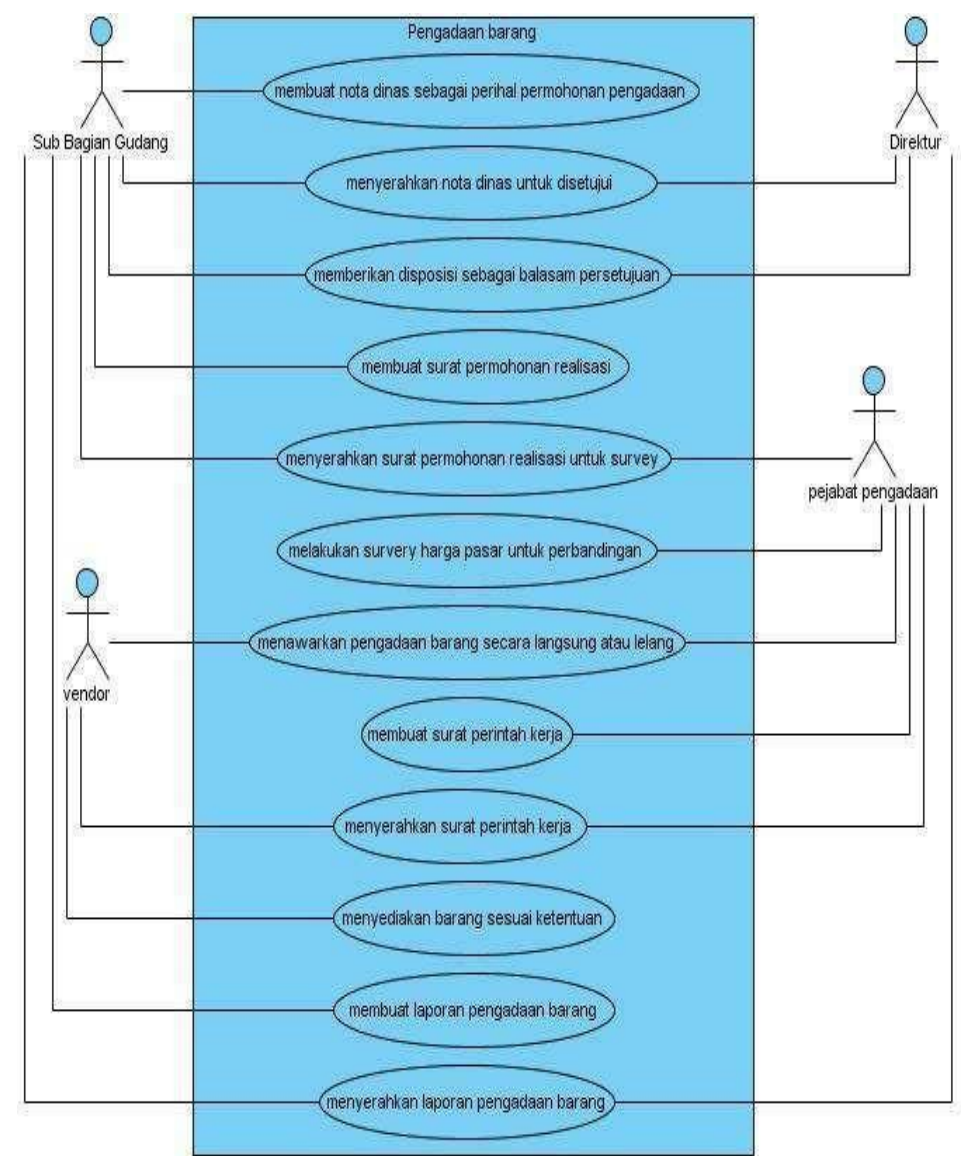

Gambar 1. Use Case Diagram Pengadaan Barang ATK (alat tulis kantor)

Gambar diatas menjelaskan tentang proses pengadaan barang yaitu, membuat nota dinas sebagai perihal permohonan pengadaan, menyerahkan nota dinas untuk disetujui, memberikan disposisi sebagai balasan persetujuan, membuat surat permohonan realisasi, menyerahkan surat permohonan realisasi untuk survey, melakukan survey harga pasar untuk perbandingan, menawarkan pengadaan barang secara langsung atau lelang, membuat surat perintah kerja, menyerahkan surat perintah kerja, menyediakan barang sesuai ketentuan, membuat laporan pengadaan barang, menyerahkan laporan pengadaan barang. 


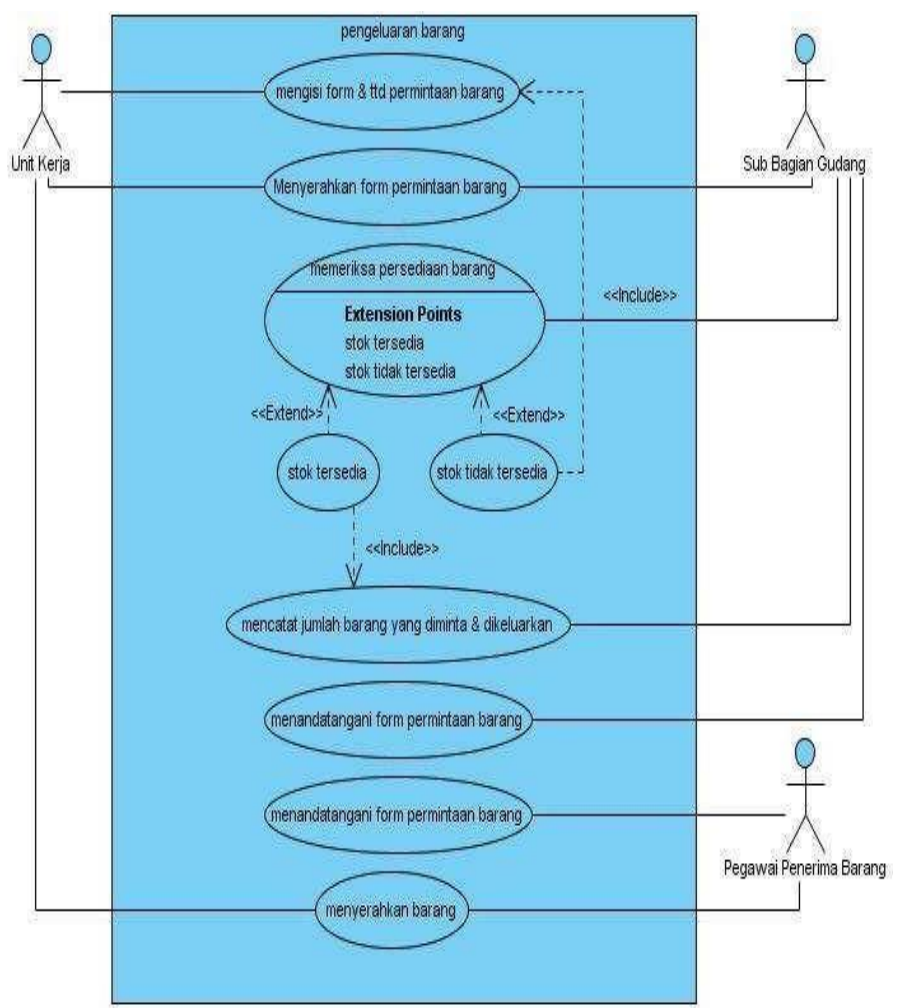

Gambar 2. Use Case Pengeluaran Barang ATK (Alat Tulis Kantor)

Gambar diatas menjelaskan tentang proses pengeluaran barang yaitu, mengisi form \& tanda tangan permintaan barang, menyerahkan form permintaan barang, memeriksa persediaan barang, mencatat jumlah barang yang diminta dan dikeluarkan, menandatangani form permintaan barang, menandatangani, form permintaan barang, menyerahkan barang.

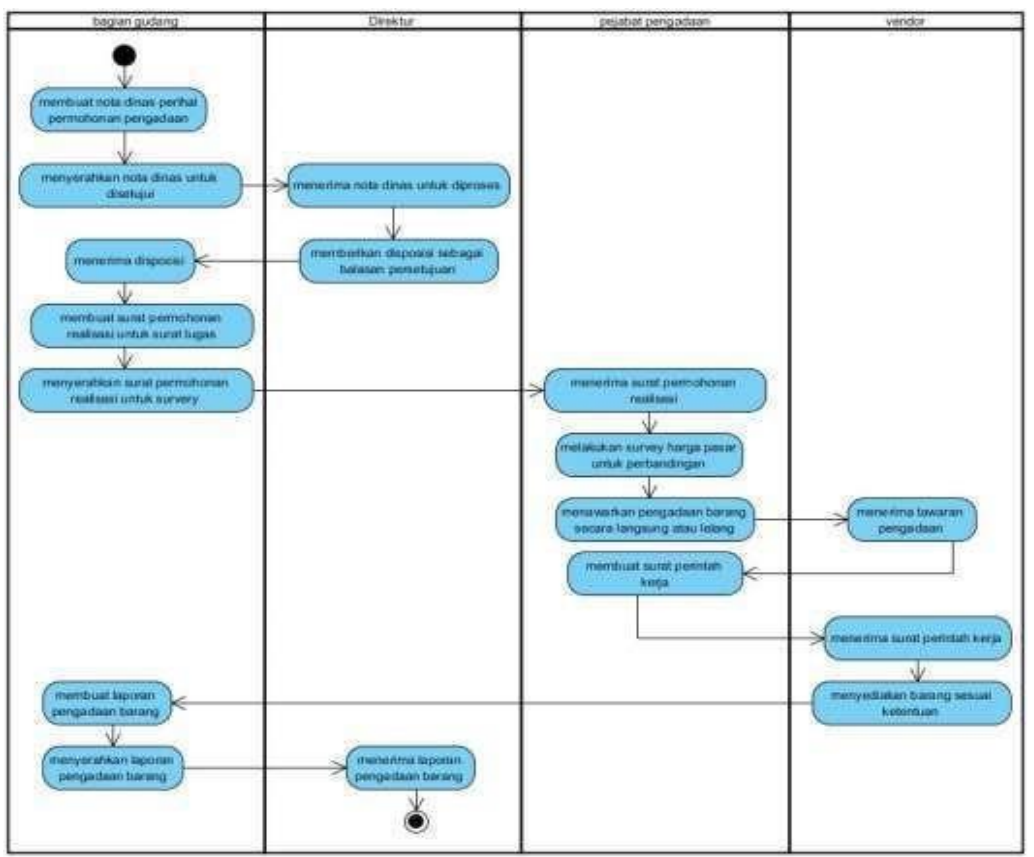

Gambar 3. Activity Diagram Pengadaan Barang Alat Tulis Kntor

Gambar diatas menjelaskan tentang proses pengadaan barang yaitu, membuat nota dinas sebagai perihal permohonan pengadaan, menyerahkan nota dinas untuk disetujui, memberikan disposisi 
sebagai balasan persetujuan, membuat surat permohonan realisasi, menyerahkan surat permohonan realisasi untuk survey, melakukan survey harga pasar untuk perbandingan, menawarkan pengadaan barang secara langsung atau lelang, membuat surat perintah kerja, menyerahkan surat perintah kerja, menyediakan barang sesuai ketentuan, membuat laporan pengadaan barang, menyerahkan laporan pengadaan barang.

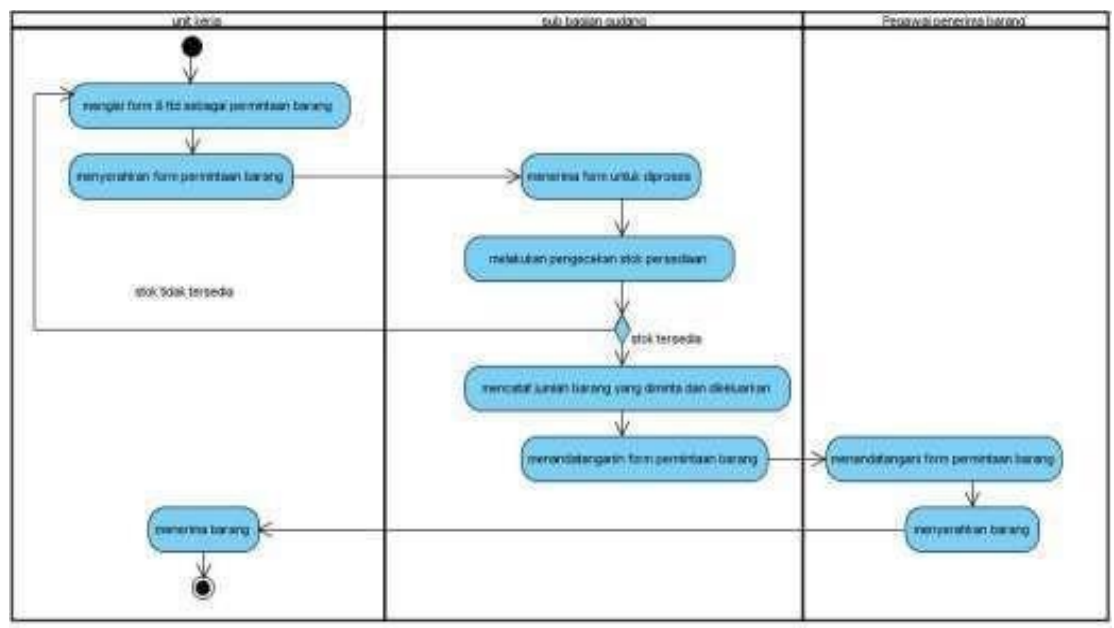

Gambar 4. Activity Diagram Pengeluaran Alat Tulis Kantor

Gambar diatas menjelaskan tentang proses pengeluaran barang yaitu, mengisi form \& tanda tangan permintaan barang, menyerahkan form permintaan barang, memeriksa persediaan barang, mencatat jumlah barang yang diminta dan dikeluarkan, menandatangani form permintaan barang, menandatangani form permintaan barang, menyerahkan barang.

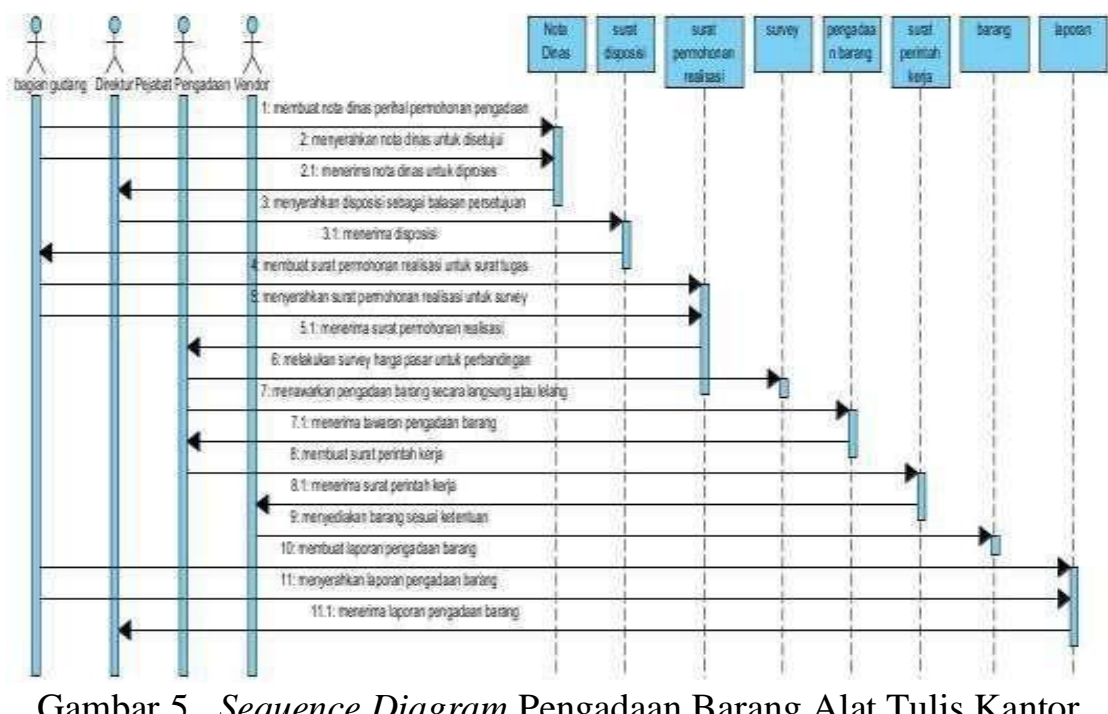

Gambar diatas menjelaskan tentang proses pengadaan barang yaitu, membuat nota dinas sebagai perihal permohonan pengadaan, menyerahkan nota dinas untuk disetujui, memberikan disposisi sebagai balasan persetujuan, membuat surat permohonan realisasi, menyerahkan surat permohonan realisasi untuk survey, melakukan survey harga pasar untuk perbandingan, menawarkan pengadaan barang secara langsung atau lelang, membuat surat perintah kerja, menyerahkan surat perintah kerja, menyediakan barang sesuai ketentuan, membuat laporan pengadaan barang, menyerahkan laporan pengadaan barang. 


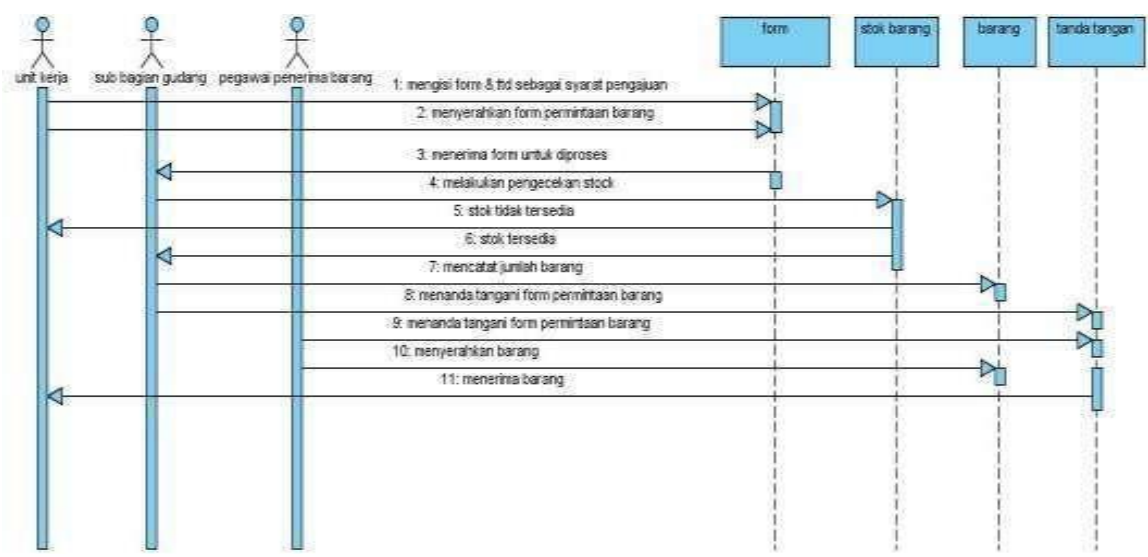

Gambar 6. Sequence Diagram Pengeluaran Barang Alat Tulis Kantor

Gambar diatas menjelaskan tentang proses pengeluaran barang yaitu, mengisi form \& tanda tangan permintaan barang, menyerahkan form permintaan barang, memeriksa persediaan barang, mencatat jumlah barang yang diminta dan dikeluarkan, menandatangani form permintaan barang, menandatangani, form permintaan barang, menyerahkan barang.

\section{Desain Rancangan Program}

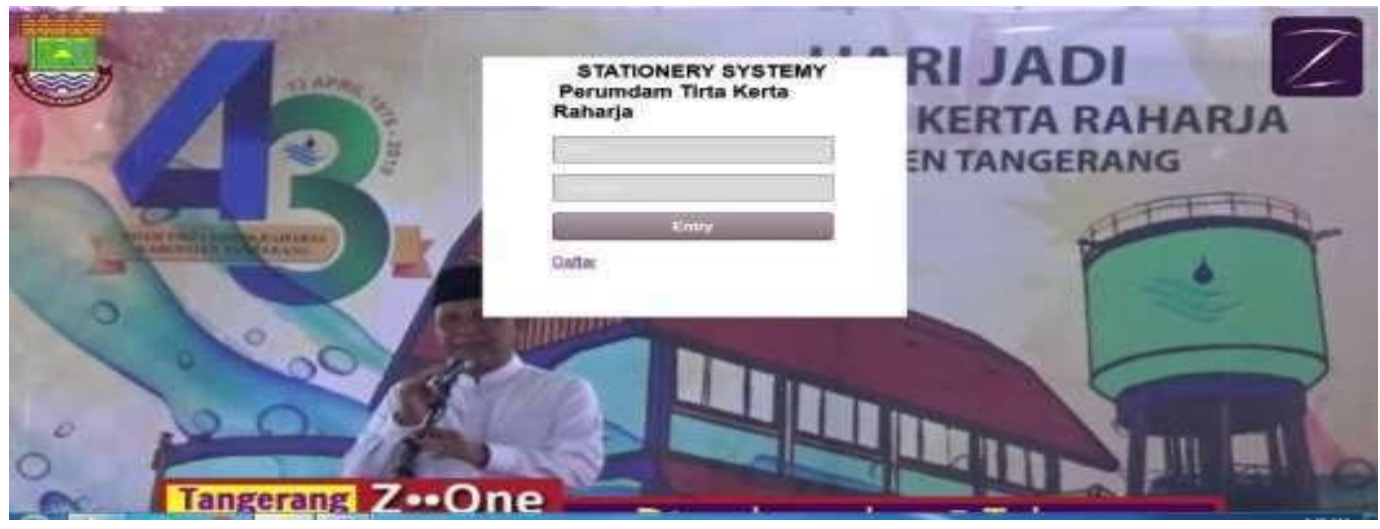

Gambar 7. Tampilan halaman Login

Gambar diatas menunjukan user harus melakukan login dengan memasukan NIPP dan password yang benar agar dapat masuk kedalam sistem.

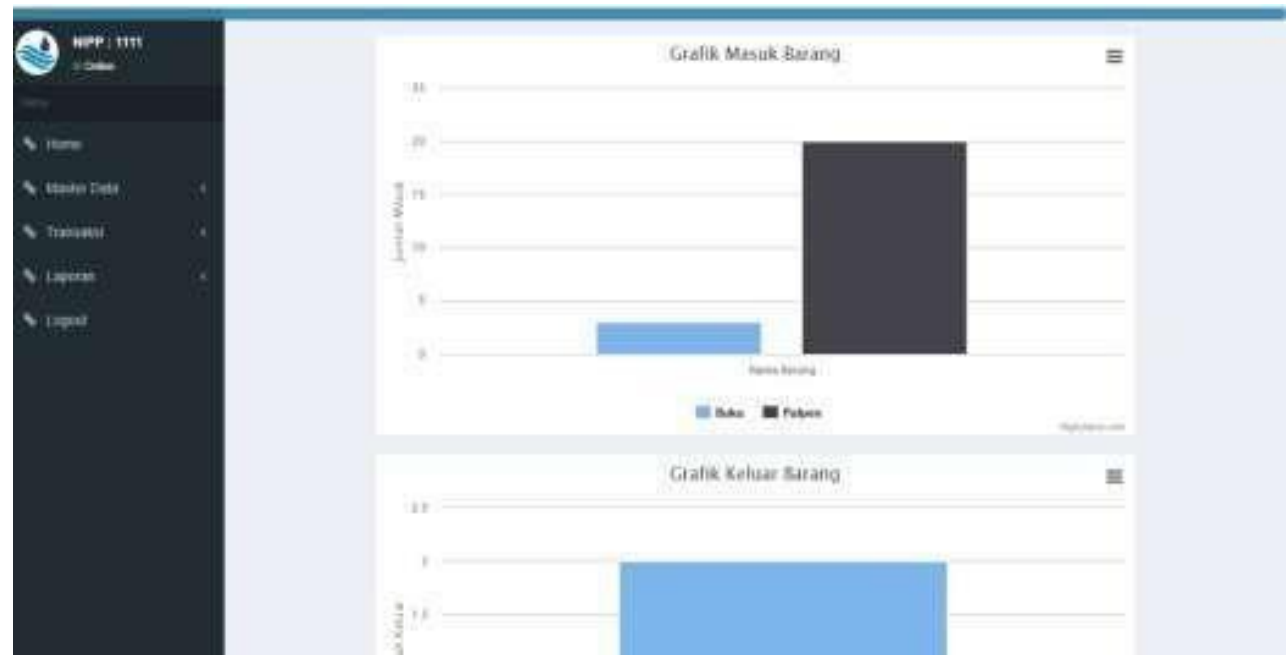




\section{Gambar 8. Tampilan halaman menu dashboard}

Gambar diatas menunjukan tampilan dari dashboard persediaan alat tulis kantor yang mana menyajikan tampilan grafik masuk barang dan keluar barang pada sistem.

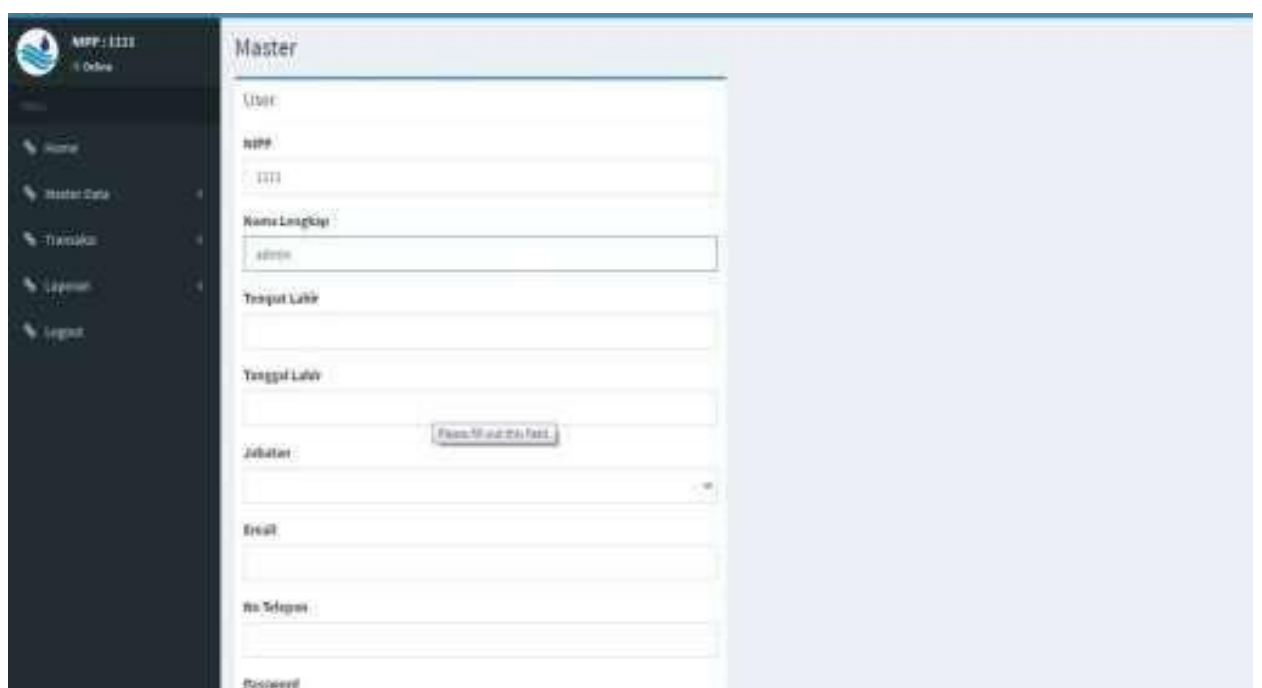

Gambar 9. Tampilan master halaman data

Gambar diatas menunjukan tampilan dari master data yang terdiri user, barang, dan supplier yang setiap sub menu dilengkapi tampilan yang berhubungan.

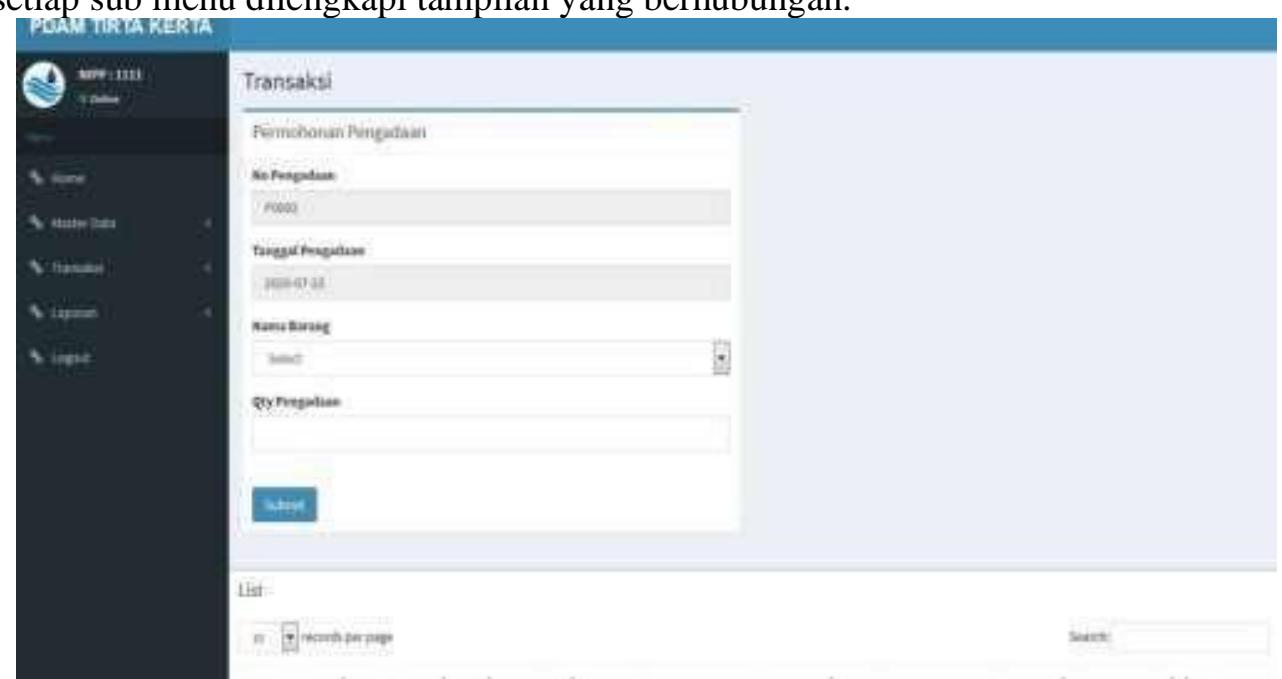

Gambar 10. Tampilan halaman transaksi permohonan pengadaan

Gambar diatas menunjukan Pada menu transaksi memiliki sub menu permohonan pengadaan yang dilengkapi dengan no pengadaan, tanggal pengadaan, nama barang, dan qty pengadaan. Setelah itu dapat di submit dan data akan terotomatis tersimpan kedalam daftar permohonon pengadaan. 


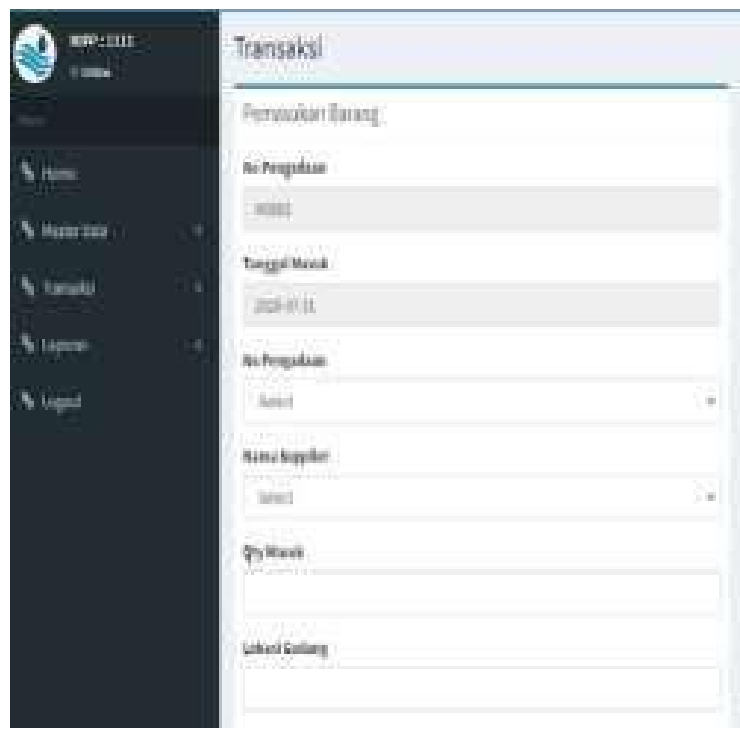

Gambar 11. Tampilan menu transaksi pemasukan barang

Gambar diatas menunjukan pada menu transaksi memiliki sub menu pemasukan barang yang dilengkapi dengan no pengadaan, tanggal masuk, no pengadaan, nama supplier, qty masuk dan lokasi gudang. Setelah itu dapat di submit dan data akan terotomatis tersimpan kedalam daftar pemasukan barang.

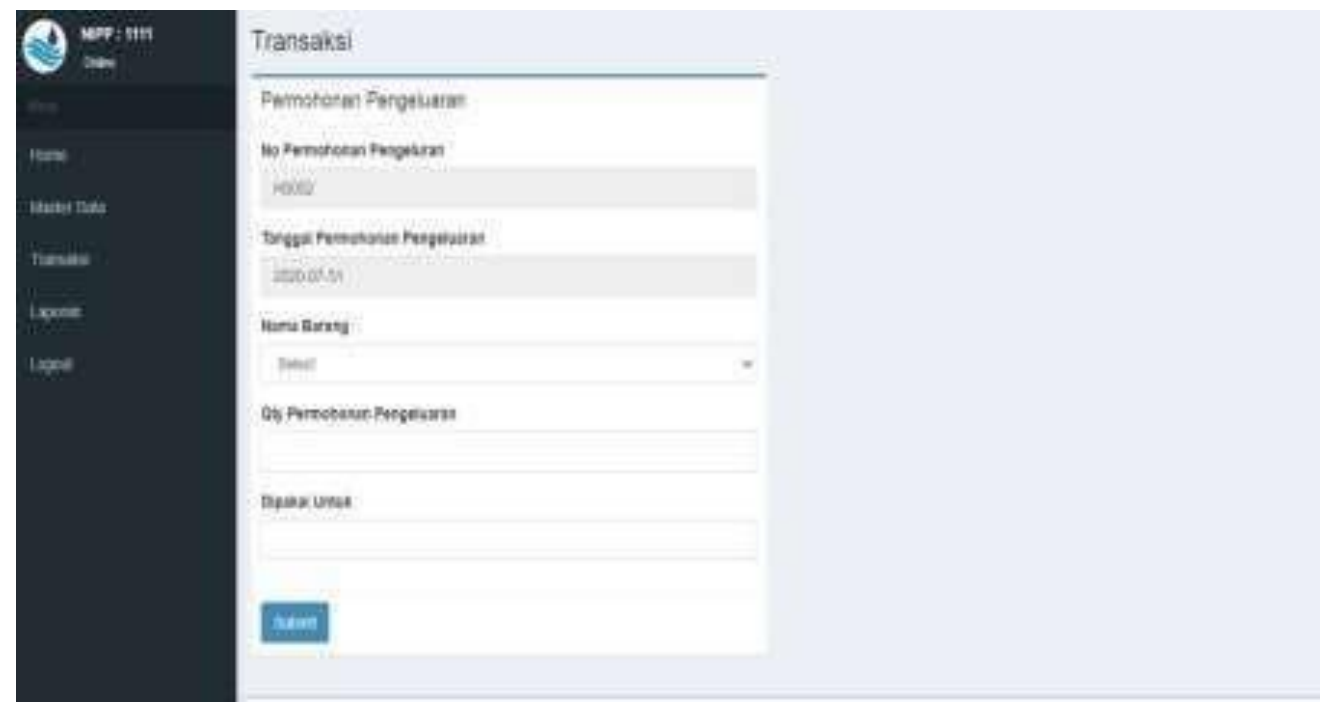

Gambar 12. Tampilan halaman permohonan pengeluaran barang

Gambar diatas menunjukan Pada menu transaksi memiliki sub menu permohonan pengeluaran yang dilengkapi dengan no permohonan pengeluaran, tanggal permohonan pengeluaran, nama barang, qty permohonan barang, dan dipakai untuk. Setelah itu dapat di submit dan data akan terotomatis tersimpan kedalam daftar permohonan barang. 


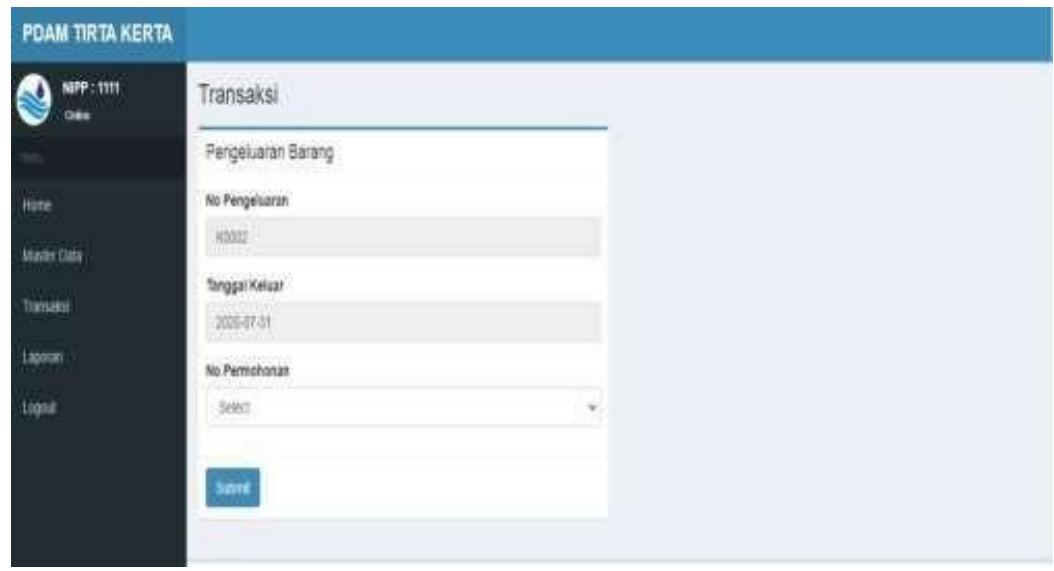

Gambar 13. Tampilan halaman transaksi pengeluaran barang

Gambar diatas menunjukan Pada menu transaksi memiliki sub menu pengeluaran barang yang dilengkapi dengan no pengeluaran, tanggal keluar, dan no permohonan. Setelah itu dapat di submit dan data akan terotomatis tersimpan kedalam daftar pengeluaran barang.
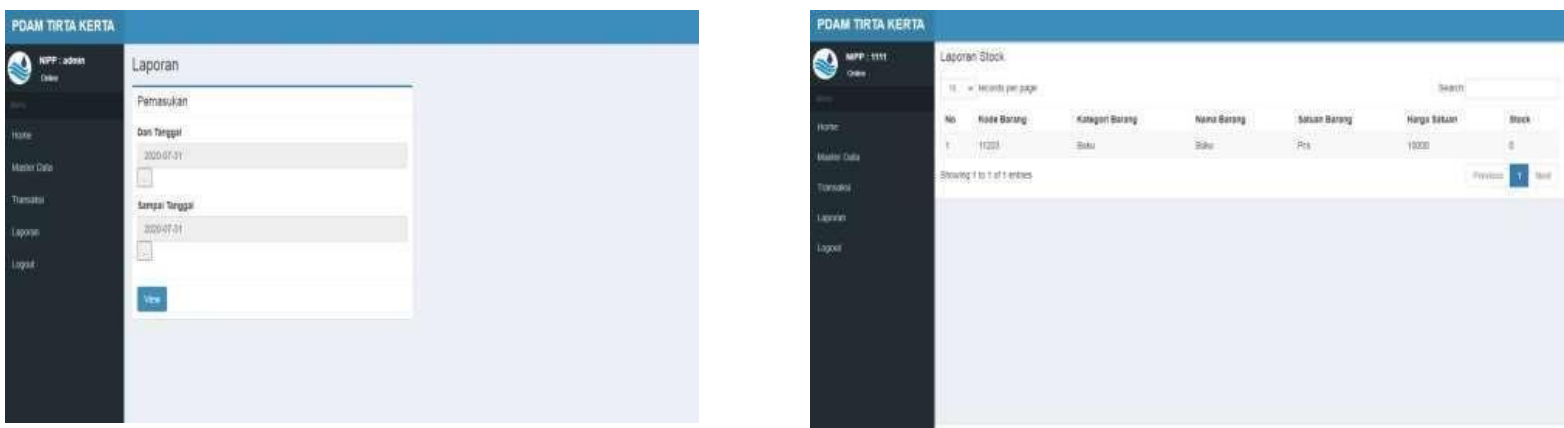

Gambar 14. Tampilan halaman menu laporan

Gambar diatas menunjukan Pada menu laporan memiliki sub menu laporan pemasukan barang, laporan pengeluaran barang dan laporan stok barang. Pada laporan pemasukan barang dilengkapi dengan tanggal pencarian seperti dari tanggal sampai tanggal berapa kemudian dapat dicetak laporan tersebut. Sedangkan laporan stok barang akan keluar sesuai stok barang yang masih tersedia.

\section{Kesimpulan}

Dengan adanya sistem yang dibuat diharapkan dapat membantu dan mempermudah pekerjaan untuk mendapatkan informasi persediaan barang alat tulis kantor, sehingga persediaan alat tulis kantor dapat terkontrol dengan baik dan dapat meminimalisasir kemungkinan error atau kesalahan yang dapat merugikan bagi penggunanya.

\section{Saran}

Diharapkan pengembangan lebih lanjut mengenai sistem informasi persediaan barang untuk menyempurnakan sistem lebih baik lagi dan meminimalisir kemungkinan terjadinya error atau kesalahan yang dapat merugikan bagi penggunanya.

Daftar Pustaka 
[1] Firman, A., Wowor, H. F., \& Najoan, X. (2016). Sistem Informasi Perpustakaan Online Berbasis Web. Jurnal Teknik Elektro dan Komputer, 5(2), 29-36.

[2] Riswanto, R., Ideliana, A., \& Kholipah, S. Media Iklan Menggunakan Aplikasi Adobe After Effek Guna Penunjang Informasi Dan Promosi Di CV. Yuka Production Kota Tangerang. Cyberpreneurship Innovative and Creative Exact and Social Science, 3(1), $11-23$.

[3] Hakim, Z., Sakuroh, L., \& Awaludin, S. (2019). Sistem Informasi Persediaan Barang Berbasis Web Pada CV Telaga Berkat. JURNAL SISFOTEK GLOBAL, 9(1).

[4] Wahyu, E. E., Fiernaningsih, N., \& Hadi, M. (2018). Penerapan Kartu Persediaan Sebagai Sarana Untuk Mempermudah Pencatatan Persediaan Pada Salon Ramanda Ampeldento Kabupaten Malang. Jurnal Administrasi dan Bisnis (adbis), 12(2), 175-181.

[5] Julianti, M. R., Dzulhaq, M. I., \& Subroto, A. (2019). Sistem Informasi Pendataan Alat Tulis Kantor Berbasis Web pada PT Astari Niagara Internasional. JURNAL SISFOTEK GLOBAL, 9(2).

[6] Triyono, T., Minarsih, D., \& Oktavia, D. (2018). Perancangan sistem informasi booking buku berbasis web pada perpustakaan SMK Pancakarya Tangerang. Journal Sensi, $4(1), 20-34$.

[7] Rahayu, S., Nurhaeni, T., \& Rohmah, M. (2015). Sistem persediaan alat tulis kantor sebagai penunjang pengambilan keputusan bagian logistik di perguruan tinggi raharja. Creative Communication and Innovative Technology Journal, 8(2), 91-101.

[8] Saryani, S., Harfizar, H., \& Ardiyansyah, A. (2019). Sistem Informasi Inventory Pemasukan dan Pengeluaran Data Barang ATK Pada Kelurahan Karangsari. Technomedia Journal, 4(1), 44-55.

[9] Winarso, D., \& Aryanto, A. (2016). Sistem Informasi Persediaan Alat Tulis Kantor Studi Kasus Pada Pt Bank Muamalat Indonesia Cabang Pekanbaru. JURNAL FASILKOM, 5(2), 1-38.

[10] Lestari, T. Y., \& Setiyadi, D. (2019). Sistem Informasi Persediaan Alat Tulis Kantor Pada PT Berjaya Sally Ceria Jakarta. INFORMATION SYSTEM FOR EDUCATORS AND PROFESSIONALS: Journal of Information System, 3(2), 163-176. 